\title{
Correction to: Biochar effects on metal bioaccumulation and arsenic speciation in alfalfa (Medicago sativa L.) grown in contaminated soil
}

\author{
M. Ibrahim ${ }^{1,2} \cdot$ S. Khan ${ }^{1,3,4} \cdot$ X. Hao ${ }^{1}$ G. Li $^{1,3} \cdot$ Y. G. Zhu ${ }^{1,5}$
}

Published online: 3 October 2017

(C) Islamic Azad University (IAU) 2017

Correction to: Int. J. Environ. Sci. Technol.

(2016) 13:2467-2474

DOI 10.1007/s13762-016-1081-5

The original version of this article unfortunately contained a mistake. One affiliation and one author were missing. The corrected affiliations and authors are given here.

The online version of the original article can be found under doi:10.1007/s13762-016-1081-5.

\section{G. Li}

gli@iue.ac.cn

1 Key Laboratory of Urban Environment and Health, Institute of Urban Environment, Chinese Academy of Sciences, Xiamen 361021, People's Republic of China

2 University of Chinese Academy of Sciences, Beijing 100049, People's Republic of China

3 Key Lab of Urban Environmental Processes and Pollution Control, Ningbo Urban Environment Observatory and Monitoring Station, Chinese Academy of Sciences, Ningbo 315830, People's Republic of China

4 Department of Environmental Sciences, University of Peshawar, Peshawar 25120, Pakistan

5 State Key Lab of Urban and Regional Ecology, Research Center for Eco-Environmental Sciences, Chinese Academy of Sciences, Beijing, People's Republic of China 